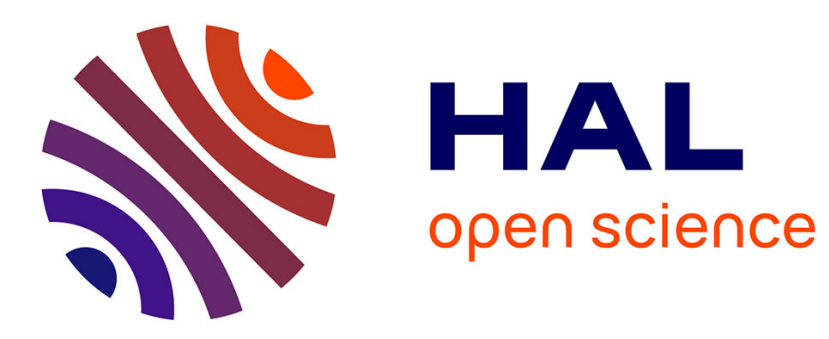

\title{
Experimental Study of Microwave Susceptibility in Ferrite Composite Materials
}

E. Flavin, F. Boust, H. Pascard

\section{To cite this version:}

E. Flavin, F. Boust, H. Pascard. Experimental Study of Microwave Susceptibility in Ferrite Composite Materials. Journal de Physique IV Proceedings, 1997, 07 (C1), pp.C1-415-C1-416. 10.1051/jp4:19971167 . jpa-00254813

\section{HAL Id: jpa-00254813 https://hal.science/jpa-00254813}

Submitted on 1 Jan 1997

HAL is a multi-disciplinary open access archive for the deposit and dissemination of scientific research documents, whether they are published or not. The documents may come from teaching and research institutions in France or abroad, or from public or private research centers.
L'archive ouverte pluridisciplinaire HAL, est destinée au dépôt et à la diffusion de documents scientifiques de niveau recherche, publiés ou non, émanant des établissements d'enseignement et de recherche français ou étrangers, des laboratoires publics ou privés. 


\title{
Experimental Study of Microwave Susceptibility in Ferrite Composite Materials
}

\author{
E. Flavin, F. Boust and H. Pascard* \\ ONERA OM, BP. 72, 92322 Châtillon cedex, France \\ * École Polytechnique, Laboratoire SESI, 91128 Palaiseau cedex, France
}

\begin{abstract}
The microwave susceptibility of $\mathrm{NiFe}_{2} \mathrm{O}_{4}$ and $\mathrm{Co}_{2} \mathrm{Z}$ was measured between 100 and $10000 \mathrm{MHz}$. The samples were either samples with different porosities or composites with different volume fractions, in the case of $\mathrm{NiFe}_{2} \mathrm{O}_{4}$, or composites with different granulometry, in the case of $\mathrm{Co}_{2} \mathrm{Z}$. The measured susceptibility undergoes substantial changes at the crossover from a ceramic state to a composite of isolated particles and for different granulometries of $\mathrm{Co}_{2} \mathrm{Z}$ in the range 10 to $600 \mu \mathrm{m}$. We show that a model in which the susceptibility is uniform inside the particles cannot account for these results. We suggest that in order to compute the susceptibility of composites, a microscopic approach is required.
\end{abstract}

\section{INTRODUCTION}

Ferrite composite materials have been the object of considerable interest for microwave applications ${ }^{1,2,3}$. The polymer matrix, with its low permittivity, allows the microwave absorption band to be enlarged ${ }^{4}$. Another interest is for processing reasons, since it is easier to cover a complex shape with a compound polymer-ferrite than with a monolithic ceramic. In both cases, if we want to optimize the final material, we have to predict the permeability of composites or, at the very least, know the different parameters which can influence it. The behaviour at high frequency of the susceptibility is very different for composites and bulk materials. The aim of this paper is to stress the difficulties in modeling by two characteristic examples. In a first part, the influence of the volume fraction in $\mathrm{NiFe}_{2} \mathrm{O}_{4}$ composites is presented and discussed. In a second part, we compare these results with the influence of granulometry in $\mathrm{CO}_{2} \mathrm{Z}$ composites.

\section{CONCENTRATION DEPENDENCE}

$\mathrm{NiFe}_{2} \mathrm{O}_{4}$ was prepared by sintering reaction. Four samples were obtained in one heat treatment $\left(1250^{\circ} \mathrm{C}\right.$ for 24 hours) with different porosities depending on the uniaxial pressure applied on the oxide powders: one bulk sample with less than $4 \%$ porosity, two porous samples with $28 \%$ and $39 \%$ porosity and one powder sample. The latter was lightly milled to be sieved under $25 \mu \mathrm{m}$ and then dispersed in a PMMA (polymethylmetacrylate) matrix with 55\% and $28 \%$ volume fraction. The susceptibility of bulk $\mathrm{NiFe}_{2} \mathrm{O}_{4}$, porous $\mathrm{NiFe}_{2} \mathrm{O}_{4}$ and composites was measured between 100 and $10000 \mathrm{MHz}$ using a HP8510 network analyser on toroidal samples placed in a coaxial wave guide at the APC7 standard.

The behaviour of the susceptibility $\left(\chi^{\prime \prime}\right)$ is given on figure 1. Two features stand out. First, for slightly the same volume fraction (composite with $55 \%$ volume fraction and porous ceramic with $62 \%$ volume fraction), the level of magnetic losses generated at low frequency $(\mathrm{f}<1000 \mathrm{MHz})$ is much lower in the composite than in the ceramic. Secondly, the natural spin resonance is strongly shifted to higher frequencies, from $1800 \mathrm{MHz}$ for bulk $\mathrm{NiFe}_{2} \mathrm{O}_{4}$ to $4500 \mathrm{MHz}$ for the composite with $28 \%$ volume fraction.

In trying to explain these results, we have used an effective medium approach. The susceptibility of an isolated particle $\chi_{\text {ext. }}$ made of a material with intrinsic susceptibility $\chi_{\mathrm{i}}$, embedded in a medium of susceptibility $\chi_{\mathrm{m}}$ is given by the relationship:

$$
\chi_{\text {ext }}=\chi_{i} /\left(1+N\left(\text { shape }, \chi_{i}, \chi_{m}\right) \cdot \chi_{i}\right)
$$

$N$, the demagnetizing factor, is a function of particle shape, $\chi_{\mathrm{i}}$ and $\chi_{\mathrm{m}}$. In the effective medium approach, the influence of other magnetic particles is taken into account by taking $\chi_{\mathrm{m}}$ as the susceptibility of the composite $\mathcal{X}$. Since $\mathcal{X}$ is a function of the volume fraction $f$, the demagnetizing factor $N$ is also a function of $f$. With $\chi=f$. $\chi$ ext, the susceptibility of the composite is given by the relationship:

$$
\chi=\frac{f \cdot \chi_{i}}{1+N\left(\text { shape }, \chi_{i}, f\right) \chi_{i}}
$$


Neglecting variations of particle shape throughout a real sample and magnetostatic interactions between particles, formula (2) is a test of a model in which the magnetic domain configuration is ignored.

Inverting relation (2), we compute $N$ for heterogenous materials, given the volume fraction, the susceptibility $\chi$ of composites and the susceptibility $\chi_{i}$ of the bulk ferrite. The result, shown on figure 2 , displays two regimes, with a crossover between 1000 and $2000 \mathrm{MHz}$.

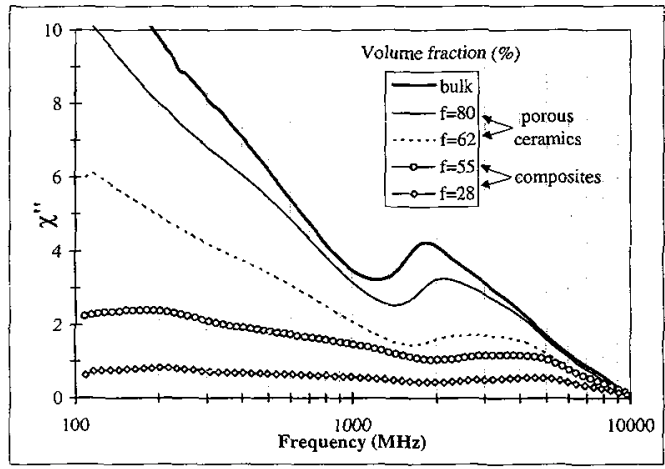

Figure 1- Imaginary part of the susceptibility as a function of volume fraction.

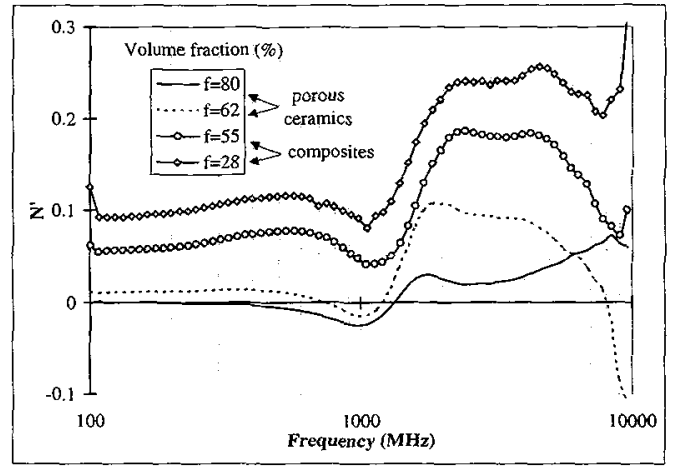

Figure 2-Real part of $N$, obtained from (2). The imaginary part of $N$ is always small except between 1 and $2 \mathrm{GHz}$.

In both regimes, $N^{\prime}$ is roughly constant with frequency and increases when the volume fraction decreases. However, $N^{\prime}$ takes two distinct values in the two regimes. This cannot be explained by the dependence of $N$ with $\chi_{i}$ (the frequency dependences of $N$ and $\chi_{\mathrm{i}}$ is very different). Thus, the two values reflect two different microscopic magnetization mechanisms: as is known, below $1000 \mathrm{MHz}$, the susceptibility comes from domain wall motion while above $2000 \mathrm{MHz}$, it comes from the natural spin resonance. To explain the difference between bulk samples and composites, the microscopic character of these mechanisms must be described.

\section{GRANULOMETRY DEPENDENCE}

The influence of granulometry was also studied for the planar hexaferrite $\mathrm{Co}_{2} \mathrm{Z}\left(\mathrm{Ba}_{3} \mathrm{Co}_{2} \mathrm{Fe}_{24} \mathrm{O}_{41}\right)$ prepared by coprecipitation ${ }^{5}$. Three granulometries were obtained $(\phi<25 \mu \mathrm{m}, 50<\phi<100 \mu \mathrm{m}$, $200<\phi<600 \mu \mathrm{m}$ ) by sieving and the powders were dispersed in a polymer matrix to obtain samples with the same volume fraction of $30 \%$.

The measured susceptibility on these samples is presented on figure 3. It shows a strong dependence with granulometry which was not observed for $\mathrm{NiFe}_{2} \mathrm{O}_{4}$ in the same granulometry range. This phenomenon cannot be accounted by the approach of the previous paragraph, the demagnetizing factor $N$ being independant of particle size. The influence of granulometry indicates a different configuration of magnetization inside particles of different size.

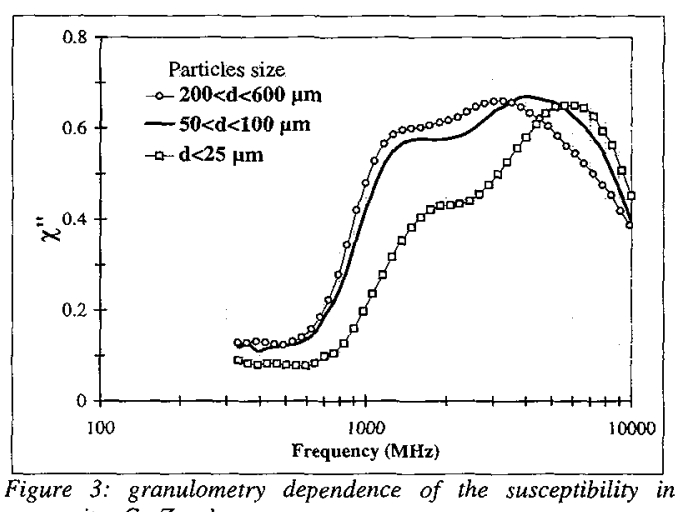

\section{CONCLUSION}

composites $\mathrm{Co}_{2} \mathrm{Z}$-polymer.

We have shown that for, $\mathrm{NiFe}_{2} \mathrm{O}_{4}$, the relation between the intrinsic susceptibility (bulk sample) and the susceptibility of composites depends on the dissipation mechanism (domain wall motion or gyromagnetic). For $\mathrm{Co}_{2} \mathrm{Z}$, the dependence of susceptibility with granulometry cannot be explained by a simple model in which magnetic structure is ignored. In both cases, in order to explain the experimental results, the topography of magnetization at a lengthscale below the particle size has to be described. To this end, we are now developping micromagnetic computations ${ }^{6}$

\footnotetext{
1 T.Nakamura, T. Tsutaoka, K.Hatakeyama, JMMM 138(1994)319-328.

2 P.Laurent et al, $4^{\text {ème }}$ JCMM, Chambéry 96, 255-258 - M. Le Floc'h et al, JMMM 140-144(1995)2191-2192.

${ }^{3}$ W.Griberger, B.Springmann, M.Brusberg, JMMM, 101(1991)173-174.

${ }^{4}$ We thank DRET/DGA for their support in pursuing this work.

5 C.Jacquiod, Thèse de doctorat, Université de Strasbourg (1994).

'P.Y.Bertin, E.Flavin, S.Labbe, L.Ramanitra, F.Henry, J.Bigot, 4 inc JCMM, Chambéry 96, 251-254.
} 